\title{
Panprotopsychism Instantiated
}

ABSTRACT: The problem of many-over-one asks how it can be that many properties are ever instantiated by one object. A putative solution might, for example, claim that the properties are appropriately bundled, or somehow tied to a bare particular. In this essay, the author argues that, surprisingly, an extant candidate solution to this problem is at the same time an independently developed candidate solution to the mind-body problem. Specifically, what is argued here to be the best version of the relata-specific bundle theory-the thesis that each instance of compresence has a special intrinsic nature in virtue of which it necessarily bundles its specific bundle-ees-is also a species of Russellian monism, labeled by David Chalmers as 'constitutive Russellian panprotopsychism'. The upshot of this connection is significant for the metaphysics of the mind-body problem: a credible theory of property instantiation turns out to have a built-in account of how consciousness is grounded in certain (broadly) physical systems.

KEYWORDS: bundle theory, compresence, Russellian monism, panprotopsychism, physicalism

\section{Introduction}

There is a potentially powerful connection between the mind-body problem and the problem of many-over-one that, to my knowledge, until now has gone unnoticed.

The mind-body problem concerns how the mind, in particular phenomenal consciousness (which I call here consciousness), relates to the physical body. For example, it is notoriously puzzling how the property of feeling pain could be instantiated by an entirely physical object, such as the nervous system. The problem of many-over-one concerns how properties (the many) relate to a given object (the one) that instantiates them (Fuhrmann I99I: 63; Rodriguez-Pereyra 2002; Ehring 20II: 4n4). Sure, one electron has charge, mass, and spin-three distinct properties. But how? Is the electron just some amalgam of its properties? Is it some construction of its properties plus some non-property entity, such as a bare particular? Or are there not really any properties, but just predicates, concepts, classes, resemblances, or fusions instrumental for classifying the electron?

The unnoticed connection between the problems concerns a pair of candidate solutions. The first, Russellian monism, addresses the mind-body problem. According to Bertrand Russell ([I927] I992), fundamental physical entities are intrinsically qualitatively special such that, when appropriately configured, they

Thank you to David Chalmers, Donovan Wishon, and several anonymous referees for very helpful feedback on earlier versions of this essay. 
necessitate the obtaining of phenomenally conscious states in macro structures like humans, where the relevant specialness outstrips standard physical theory. Rather than try to define 'fundamental' or 'intrinsic', I offer the following rough glosses: Let ' $\mathrm{F}$ ' name your favorite structuring relation relevant to metaphysical explanation, perhaps grounding, dependence, essence, or the like. Now-helping myself to plural quantification-let the fundamentalia be the entities $x x$ such that, for all entities $y y$ that are not one of $x x$, it is not the case that the nature or existence of $x x$ is explained by any of $y y$ bearing $\mathrm{F}$ to $x x$. As for 'intrinsic', the standard first approximation suffices: an object's intrinsic properties are those that it has independently of disjoint objects.

Russellian monism comes in two varieties: panpsychist and panprotopsychist. The former holds that the special intrinsic properties are themselves consciousness properties; the latter denies this. Although I briefly touch on panpsychism, my primary focus is on panprotopsychist Russellian monism.

The second candidate solution, 'relata-specific' bundle theory, addresses the many-over-one (Maurin 2002; Wieland and Betti 2008). On this approach, objects are bundles of properties or property instances, the latter of which may be tropes (that is, qualitatively fine-grained property instances, where properties are not universals); for an object to possess a property $\mathrm{F}$ is for $\mathrm{F}$ (or an $\mathrm{F}$ trope) to be in the relevant bundle; and a given bundle exists, qua bundle, as a necessary result of the existence and intrinsic nature of a primitive bundling relation instance. I characterize relata-specific bundle theory disjunctively as between properties (which may be universals) and tropes in the interest of ontological neutrality.

The advertised connection is intimate: the best available version of relata-specific bundle theory is a species of panprotopsychist Russellian monism. For the qualitatively special instances of the primitive bundling relation that the best version of relata-specific bundle theory deploys to explain metaphysically the instantiation of fundamental physical properties by fundamental physical entities also collectively metaphysically explain the instantiation of phenomenal consciousness properties by macro physical structures.

Notice that the payoff is principally metaphysical: a credible theory of general property instantiation turns out to contain a built-in explanation of how physical systems (broadly construed) ground consciousness properties. Whether the resulting picture also helps close the epistemic gap between the mind and the body is less clear, although certain ways of answering affirmatively are defensible.

One motivation for Russellian monism concerns conceivability and causal closure (Chalmers 20I5). Unlike orthodox physicalism, Russellian monism is untouched by the zombie argument (Chalmers 1996) and the knowledge argument (Jackson I982), since, on an appropriately liberal conception of physical properties, it entails that zombies and Jackson's Mary are inconceivable: your physical duplicates are thereby your phenomenal duplicates, on this conception, and Mary's knowing all physical facts would entail, by universal elimination, her knowing each phenomenal fact. Moreover, unlike dualism, Russellian monism straightforwardly accommodates the intuition that the physical realm is causally closed and yet mentality is causally efficacious. For according to Russellian monism, macro mental properties are determined by the fundamentally 
physical (still broadly construed) just as much as any macro physical properties are so determined, yet the latter are causally efficacious.

One motivation for relata-specific bundle theory is that it yields an elegant solution to Bradley's regress, according to which contingent relations obtain only in virtue of further contingent relations obtaining, and so on ad infinitum (Bradley I 893; Maurin 2002; Wieland and Betti 2008). For if the unique qualitative nature of each particular bundling relation instance primitively necessitates the bundling of its relata (some of which are contingent relations/properties) then no other relation is needed to explain contingent relation or property instantiation. (For expository purposes, I apply 'Bradley's regress' loosely throughout to several similar problems about how relations relate. I do not claim precise representation of the historical F. H. Bradley.)

If the best version of relata-specific bundle theory is a species of Russellian monism, then these motivating features aggregate. Namely, a candidate solution to the many-over-one and Bradley's regress is, when appropriately constrained, also a candidate solution to the mind-body problem that avoids zombies, Mary, and causal exclusion. Thus friends of relata-specific bundle theory and Russellian monism alike have reason to welcome the proposed connection as dialectically promising.

With that said, it is not my goal to argue for Russellian monism or relata-specific bundle theory. Any worthwhile defense of either theory would require more space than I have here. Nor do I claim that the motivations for the relata-specific bundle theory version of Russellian monism are all and only the motivations for more traditional Russellian monism. The thesis is that the best version of relata-specific bundle theory does everything required of a theory in order to be a species of Russellian monism; sound arguments for this thesis need not look like familiar arguments for Russellian monism. Moreover, while I argue that the best version of relata-specific bundle theory is a version of Russellian monism, I do not argue that the best version of Russellian monism is a version of relata-specific bundle theory. I believe antecedent proponents of Russellian monism should consider endorsing relata-specific bundle theory Russellian monism, but I do not argue that they are forced to do so under power of theoretical advantage. My goals are only to show that Russellian monism and relata-specific bundle theory connect in the way described and to explore some consequences of the connection. (It bears mentioning, however, that it is an open question whether the dialectical advantages that David Chalmers attributes to Russellian monism are independent of the many-over-one. I suspect both that they are not and that their preservation motivates relata-specific bundle theory Russellian monism, precisely because of relata-specific bundle theory's modal force. Bradley's challenge prompts inquiry into whether the special intrinsic properties posited by Russellian monism, the relevant physical dispositional structures, and the (non-relata-specific bundle theoretic) instantiation or compresence instances assumed to tie the properties with the structures, all could have existed without interrelating as per Russellian monism, thereby calling into question whether those properties ground those structures. Since relata-specific bundle theory's modal force preempts this question, relata-specific bundle theory may well be of dialectical service to Russellian monism.) 
For readers unsure about the importance of Russellian monism and relata-specific bundle theory, I point to their respective literatures. Chalmers (2003, 20I 5 ), Philip Goff (2017), and numerous others motivate Russellian monism along the lines described above. Motivation for relata-specific bundle theory is less well known, but still robust. For example, relata-specific bundle theory qua solution to Bradley's regress is motivated by default once one rejects (I) property nominalism and (2) David Armstrong's states of affairs ontology, the latter of which attempts to preempt Bradley's challenge by making particulars-instantiating-universals fundamental. After all, the remaining competitive ontologies of propertiesbundle theories and substance-attribute theories-must address Bradley's challenge. To see that the default case is there to be made, notice that many, including Armstrong (1978, 1989), have argued forcefully against property nominalism, and that others, including one of the original developers of relata-specific bundle theory, Anna-Sofia Maurin (20I 5, 20I6), have argued forcefully against Armstrong's states of affairs ontology. Granted, resemblance nominalism and mereological nominalism have proven more resilient than Armstrong's early arguments against them indicate (see Rodriguez-Pereyra 2002; Effingham 2020). But those two interesting positions remain objectionable. Resemblance nominalism requires commitment to Lewisian modal realism, and makes a tomato's possession of redness turn on what Santa hats are like. Mereological nominalism entails that (part of) redness tastes like wine and (or) sounds like a cardinal and is incompatible with mereological junk, a structure every element of which is a proper part of some others (Bohn 2009).

\section{Russellian Monism and Panprotopsychism}

Recent interest in Russellian monism is due largely to Daniel Stoljar and Chalmers, who have influentially clarified the relationship between physicalism and Russellian monism (Stoljar 200I; Chalmers 2003). Below I follow the framing and updated terminology of (Chalmers 2015), which builds up to panprotopsychist Russellian monism by first discussing panpsychist Russellian monism.

Let 'microphenomenal' properties be those that panpsychists attribute to fundamental physical particles as the realizers/role players of fundamental physical dispositional structure. Let 'constitutive Russellian panpsychism' name the view that microphenomenal properties metaphysically explain consciousness in macro entities like humans. In Chalmers's terminology, the 'microphenomenal constitutes the macrophenomenal', where 'constitutes' is cashed out in terms of grounding. Without getting into the contemporary grounding debates, I take the key features of 'constituting' properties to be that their instances are (I) qualitative, in a sense relevant to explanation, (2) spatiotemporally configurable, and (3) metaphysically responsible-in part because of their qualitative nature-for the exemplification of certain other properties. So F properties are constitutive of $G$ properties just in case the intrinsic qualitative nature of appropriately spatiotemporally configured $\mathrm{F}$ instances is responsible for the exemplification of $G$ with respect to the relevant configuration. I will not try to define 'qualitative', but the basic idea is that qualitative properties are not essentially concerned with specific individuals; rather, they confer resemblance, causal, or other individual-independent statuses 
onto their bearers. Thus being the best supporting actor is qualitative, but being Morgan Freeman is not. The focus on intrinsic qualitative nature reflects the explanatory element of grounding, as opposed to less clearly explanatory relations like supervenience. As Jaegwon Kim (I987) and Stephen Schiffer (I987) independently noted decades ago, supervenience need not be tied in any explanatory way to the qualitative natures of the subvening or supervening properties. In the case of grounding, by contrast, the qualitative nature of the ground and grounded are typically assumed to be explanatorily important. I take it that one reason Chalmers appeals to ground in characterizing 'constitutes' is that Russellian monism is supposed to be explanatory, not merely modally adequate.

Still following Chalmers, let 'panprotopsychism' name the view that fundamental physical entities exemplify 'protophenomenal' properties, which are (I) non-phenomenal; (2) nonstructural (which involves being both intrinsic [as opposed to extrinsic] and categorical [as opposed to dispositional]); (3) capable of constituting macrophenomenal properties; and (4) such that truths about them a priori entail truths about the phenomenal properties that they constitute. Let 'constitutive Russellian panprotopsychism' name the view that the protophenomenal properties of fundamental physical entities constitute all macrophenomenal properties and are the realizers/role players of fundamental physical dispositional structures. Although I continue to use Russellian monism for convenience, it is constitutive Russellian panprotopsychism that interests me below, and of which I argue that the best version of relata-specific bundle theory is a species.

Notice that if physics concerns only dispositional structures-what Chalmers calls 'narrow' physical properties (and much like what Stoljar [200I] calls ' $t$-physical' properties)—then Russellian monism is not a form of physicalism, for it invokes categorical properties-what Chalmers calls 'quiddities'-to ground physics. However, if physics concerns both dispositional structure and the realizers/role players relevant to the structure-what Chalmers calls 'broadly' physical properties-then Russellian monism is a form of physicalism. As Chalmers emphasizes, this issue is largely verbal. The dialectical features I note in the introduction, by contrast, are substantive: on the broad conception of physicality, Russellian monism rules out zombies and Mary as inconceivable and yet leaves room for phenomenal properties to be causally efficacious without violating the causal closure of the physical. Since Russellian monism requires the broad conception, it enjoys these benefits.

\section{The Relata-Specific Theory of Instantiation}

The relata-specific theory of instantiation (relata-specific bundle theory) is a version of bundle theory developed as a solution to Bradley's relation regress (Bradley I893; Maurin 2002; Wieland and Betti 2008; see also MacBride 20II). The basic idea underlying Bradley's regress is that relata $x$ and $y$ are related by contingent relation $\mathrm{R}_{\mathrm{I}}$ only if some further contingent relation $\mathrm{R}_{2}$-for example, instantiation-relates $x$ and $y$ to $\mathrm{R}_{\mathrm{I}}$. Otherwise, qua contingent, $\mathrm{R}_{\mathrm{I}}$ could exist alongside both $x$ and $y$ without relating them. Given this basic idea, however, some yet further contingent 
relation $\mathrm{R}_{3}$ is needed to relate $\mathrm{R}_{2}$ to $\mathrm{R}_{\mathrm{I}}$ and $x$ and $y$, prompting an explanation for how $\mathrm{R}_{3}$ relates its relata, and so on.

Bundle theorists treat property instantiation in terms of a bundling relation among universals or tropes. Let ' $\mathrm{C}$ ' (for 'compresence') name this relation. It is convenient to treat property and relation instances here as tropes, although they could also be instances of universals. (I remain ontologically neutral, but often speak of tropes.) Either way, it is crucial to recognize that these property and relation instances are spatiotemporally located particulars. This is standard for trope theory (see Williams I953; Campbell I990; Ehring 20II), but also is commonplace for universal bundle theories (see, for example, O'Leary-Hawthorne and Cover 1998). After all, if the compresence relation instances were not spatiotemporally located, then it would be unclear why any universal properties or relations should be spatiotemporally located, or immanent. For once we are willing to accept non-spatiotemporally-located entities in our metaphysics of properties of material objects, we may as well be Platonists about universals, given Platonism's apparent advantages with respect to semantics, mathematics, and modality (see Bealer I993; Carmichael 2010). Yet Platonic or transcendent universal ontologies are discordant with bundle theory, since material objects are not bundles of non-spatiotemporal entities. Let there be no confusion, then, about talk of intrinsic, qualitative natures of compresence relation instances: such instances are just as spatiotemporally located and particular as Mont Blanc, and just as fit to bear intrinsic, qualitative natures.

Thus the bundle theorist's solution to the many-over-one is that many properties are instantiated by one object just in case they or their tropes are bundled by an instance of C. For example, the bundle theorist's (noncausal) explanation for my car's being green, rather than red, is that the car is a property bundle that contains a greenness trope rather than a redness trope; and it contains the greenness trope because the latter is bundled with the car's other tropes by a $\mathrm{C}$ instance. The problem from Bradley's regress, then, is to explain why some $\mathrm{C}$ instance alone is sufficient to bundle the greenness trope in the car bundle. After all, it would seem that the greenness trope, the $\mathrm{C}$ instance, and the car's other greenness-independent tropes could all have existed without the $\mathrm{C}$ instance bundling them, unless perhaps some further $\mathrm{C}$ instance were around, in which case the problem simply regenerates.

Relata-specific bundle theory's key explanatory claim is that $\mathrm{C}$ instances are primitively natured to be fundamentally relata-specific, in that each necessitates the bundling of its bundle-ees. Given this necessity, no further $\mathrm{C}$ instance is needed to account for the first's bundling success. Thus there is no regress involving $\mathrm{C}$ and any of its relata. For example, the $\mathrm{C}$ instance $\mathrm{C}_{\mathrm{car}}$ that bundles my car's properties could not have failed to bundle the greenness trope, given (I) $\mathrm{C}_{\text {car }}$ 's specific nature and (2) that $\mathrm{C}_{\mathrm{car}}$ exists. Notice, however, that relata-specific bundle theory does not entail that if some $\mathrm{C}$ instance $\mathrm{C}_{x}$ bundles property instances $F_{x}$ and $G_{x}$ then $C_{x}$ is necessary for the existence of $F_{x}$ or $G_{x}$. Whether it is necessary for their exact co-bundling (as opposed to their existence) is an interesting issue, but not one that I explore here. What matters here is its sufficiency for their exact co-bundling. 
In describing relata-specific bundle theory, Maurin writes, 'there is something about a particular compresence-trope that justifies the positing of necessary connections that, according to the present proposal, hold between it and the entities that it relates' (2002: I66, Maurin's emphasis; Maurin's 'compresencetrope' is roughly synonymous with my ' $\mathrm{C}$ instance'). And Wieland and Betti explain, if a relation [instance] is relata-specific, it is in its own nature to relate specific relata. Suppose. . . that the relation of standing two feet away $R$ holds between $a$ and $b$. Then, if $R$ is relata-specific, [the instance of] it [that] relates $a$ and $b$ [does so] as soon as it exists' (2008: 5 I 8$)$. I added the interpolation because I assume that Wieland and Betti-like Maurin-are principally concerned not with a relation per se, but with instances of a given relation. For their view surely is not that $a$ and $b$ are related as soon as R exists. That is clearly false: $c$ and $d$ (each distinct from each of $a$ and $b$ ) might be related by $\mathrm{R}$ at some world that does not contain $a$ and $b$ whatsoever. What matters for relata-specific bundle theory is the instance of $\mathrm{R}$ that in fact relates $a$ and $b$.

Thus whatever the 'something about' a $\mathrm{C}$ instance is, it is unique to that $\mathrm{C}$ instance -whether qualitatively unique or merely numerically unique. Simply being some compresence trope or other is insufficient. Neither Maurin nor Wieland and Betti explicitly say that the unique 'something about' or 'nature' of a given $\mathrm{C}$ instance is an intrinsic, categorical, qualitative feature of the $\mathrm{C}$ instance, as opposed to being extrinsic or relational, dispositional or structural, or non-qualitative or haecceitistic. However, I argue below that charity motivates the former interpretation. More importantly-since exegesis of relata-specific bundle theory's early developers is not my interest-the best version of relata-specific bundle theory requires that the crucial bundle-explaining feature of a given $\mathrm{C}$ instance is intrinsic, categorical, and qualitative.

The case for intrinsicality is straightforward. If the 'something about' the $\mathrm{C}$ instance were extrinsic to it then the $\mathrm{C}$ instance alone would be insufficient for bundling. But the guiding claim of relata-specific bundle theory is precisely that a given $\mathrm{C}$ instance alone is thusly sufficient. Intrinsicality is further supported by Wieland and Betti's talk of the relevant nature being the C instance's 'own', and of the $\mathrm{C}$ instance necessitating the bundling 'as soon as it exists'.

One might object that a $\mathrm{C}$ instance's dependence on its relata indicates a lack of intrinsic nature. But this is a confusion. A relation instance's dependence on its relata need not preclude intrinsic nature. Suppose a fundamental force bonds two particles; that bonding instance has an intrinsic nature informed by the relevant force, its dependence on its relata notwithstanding.

The case for categoricity proceeds by dilemma. To begin, note that if a given $\mathrm{C}$ instance's bundle-explaining nature is dispositional, the relevant disposition must be a bare disposition (one not based in categorical properties of the $\mathrm{C}$ instance), lest intrinsic categoricity be crucial to the bundling status of $\mathrm{C}$ instances. Now, if the relevant 'nature' of a given $\mathrm{C}$ instance is dispositional, then either it manifests essentially (first horn) or not (second horn). If it does (perhaps with the bundling itself being the lone manifestation condition), then the resulting bundle theory says that a categorically bare particular (a C instance) explains bundling, that this bare $\mathrm{C}$ instance is essentially fit to unify a certain group of properties into an object, 
and that it is primitively numerically distinct from other such bare unifiers of properties. While this is not mainstream bare particular theory (since it ties each bare unifier to a specific group of properties essentially), it does violate bundle theory's prohibition on particulars whose categorically bare particularity is essentially disposed to unify properties into objects. Suppose, then, that the putatively dispositional $\mathrm{C}$ instance does not manifest essentially (second horn). It follows that something outside the $\mathrm{C}$ instance is required in order for the $\mathrm{C}$ instance to explain/necessitate bundling, namely, the satisfaction of the manifestation conditions. This is inconsistent with the claim that the $\mathrm{C}$ instance bundles its relata as soon as it exists, since it could then be exemplified without its manifestation conditions being met, thereby prohibiting bundling.

To make the key feature structural in some more general way prompts the question of why the particular categorical instantiator(s) of the structure in question enables the bundling, as opposed to some other categorical instantiator(s). The question then arises of whether some further relation is needed to explain that this instantiator is at work. Yet this is just the kind of question that relata-specific bundle theory is supposed to answer, not to generate.

The case for qualitativeness is more complicated. Consider material objects $a$ and $b$. Let $a$ be a bundle of three tropes $\mathrm{F}_{\mathrm{I}}, \mathrm{G}_{\mathrm{I}}$, and $\mathrm{H}_{\mathrm{I}}$, bundled by $\mathrm{C}$ instance $\mathrm{C}_{\mathrm{I}}$; and let $a, \mathrm{~F}_{\mathrm{I}}, \mathrm{G}_{\mathrm{I}}, \mathrm{H}_{\mathrm{I}}$, and $\mathrm{C}_{\mathrm{I}}$ all be exactly located at location $l_{\mathrm{I}}$. Let $b$ be a bundle of the tropes $F_{2}, G_{2}, H_{2}$, and $K_{2}$ (each distinct from each of $F_{I}, G_{I}$, and $H_{I}$ ), bundled by $\mathrm{C}$ instance $\mathrm{C}_{2}$; and let $b, \mathrm{~F}_{2}, \mathrm{G}_{2}, \mathrm{H}_{2}, \mathrm{~K}_{2}$, and $\mathrm{C}_{2}$ all be exactly located at location $l_{2}$ (distinct from $l_{\mathrm{I}}$ ). The following question is the sort that relata-specific bundle theory is supposed to answer: what ultimately explains why no $\mathrm{K}$ trope is bundled with $F_{I}, G_{I}$, and $H_{I}$ ? Following Maurin and Wieland and Betti, the relata-specific bundle theorist's answer is that there is 'something about' $\mathrm{C}_{\mathrm{I}}$ - its 'own nature'that necessitates its bundling exactly $F_{I}, G_{I}$, and $H_{I}$, and thus not $K_{2}$ or any other $\mathrm{K}$ trope. We have already seen that this 'something about' $\mathrm{C}_{\mathrm{I}}$ cannot be the general qualitative nature of compresence, since both $C_{I}$ and $C_{2}$ have that general nature, and yet $\mathrm{C}_{2}$ does nothing to explain why there is no bundle consisting exactly of $F_{I}, G_{I}, H_{I}$, and some $K$ trope. Rather, the relevant 'nature' of $C_{I}$ is its 'own'-it is unique to $\mathrm{C}_{\mathrm{I}}$.

The argument that $\mathrm{C}_{\mathrm{I}}$ 's unique nature must be qualitative proceeds by elimination of alternatives. I see three competitors worth considering. According to the first, the relevant 'something about' $\mathrm{C}_{\mathrm{I}}$ is $(\mathrm{I})$ its being exactly located at $l_{\mathrm{I}}$; according to the second it is (2) some unique non-qualitative but constituent 'nature' that primitively individuates $C_{1}$ from $C_{2}$ and all other tropes; and according to the third it is (3) a brute fact-one not dependent on anything intrinsic to $C_{I}$ securing that $\mathrm{C}_{\mathrm{I}}$ is distinct from $\mathrm{C}_{2}$. (A referee suggests as a fourth option a brute fact that does depend on some non-qualitative nature of $\mathrm{C}_{\mathrm{I}}$. Below $\mathrm{I}$ argue that option (2) fails because bundle theory prohibits such natures. This fourth option faces the same problem.)

Each of these competitors fails. $l_{\mathrm{I}}$ cannot do the job unless it is the only possible location for $C_{I}$. Otherwise, there are worlds at which $C_{I}$ is located at another location and yet still bundles $F_{I}, G_{I}$, and $H_{I}$ (since it bundles exactly those tropes whenever it exists), which would undermine the claim that $\mathrm{C}_{\mathrm{I}}$ 's location at $l_{\mathrm{I}}$ 
determines its bundling power. But there is little reason to think that the best version of relata-specific bundle theory requires each $\mathrm{C}$ instance to have its location essentially. This would be unmotivated and ad hoc unless one required all tropes to have their locations essentially, which is prohibitively controversial. Moreover, even if $F_{I}, G_{I}$, and $H_{I}$ were assumed to be essentially located at $l_{\mathrm{I}}$, it is possible for them to be bundled with more tropes at $l_{\mathrm{I}}$ than there actually are. Consider a world that consists only of $l_{\mathrm{I}}$ and its contents at that world, and at which $\mathrm{F}_{\mathrm{I}}, \mathrm{G}_{\mathrm{I}}$, $\mathrm{H}_{\mathrm{I}}$, and a fourth trope $\mathrm{K}_{\mathrm{I}}$ are co-bundled at $l_{\mathrm{I}}$. This is a plausible possible world, since its description is schematic and contains no logical or conceptual incoherence. Now, according to relata-specific bundle theory, the world in question must contain a $C$ instance to account for the fact that $F_{I}, G_{I}, H_{I}$, and $K_{I}$ are bundled. But the only available exact location for this $\mathrm{C}$ instance, by stipulation, is $l_{\mathrm{I}}$. Yet the $\mathrm{C}$ instance in question cannot be numerically identical with $C_{I}$ since the latter necessarily bundles exactly $F_{I}, G_{I}$, and $H_{I}$ (to the exclusion of $\mathrm{K}_{\mathrm{I}}$ ) 'as soon as it exists'. Thus the $\mathrm{C}$ instance doing the bundling at the relevant world cannot be $\mathrm{C}_{\mathrm{I}}$, and yet is located at $l_{\mathrm{I}}$. Consequently, being located at $l_{\mathrm{I}}$ cannot be that in virtue of which $\mathrm{C}_{\mathrm{I}}$ is the bundler of exactly $\mathrm{F}_{\mathrm{I}}, \mathrm{G}_{\mathrm{I}}$, and $\mathrm{H}_{\mathrm{I}}$ at the original world described.

Nor can the relevant 'something about' $C_{I}$ be alternative (2): a non-qualitative constituent 'nature' that is primitively responsible for $\mathrm{C}_{\mathrm{I}}$ 's individuation. For bundle theory denies that tropes or universals possess haecceities, bare particulars, or any other such primitive individuators as constituents. Moreover, alternative (2) prompts the question of why that haecceity or bare particular is the one that necessitates the bundling of exactly $F_{I}, G_{I}$, and $H_{I}$, rather than some other. The answer must be that there is 'something about' that haecceity or bare particular, which could not then be some non-qualitative constituent, since haecceities and bare particulars lack further haecceities and bare particulars.

Nor can the 'something about' $C_{I}$ be alternative (3): a brute fact involving $C_{I}$, which obtains independently of the intrinsic status of $\mathrm{C}_{\mathrm{r}}$. Relata-specific bundle theory would then have no way to distinguish worlds where $\mathrm{C}$ instances bundle certain tropes from worlds that do not. Indeed, alternative (3) allows that there is some possible world $w$ qualitatively exactly like the actual world, yet entirely devoid of electrons. To see this, suppose that for every $\mathrm{C}$ instance at the actual world that bundles the tropes of an electron, $w$ contains a qualitatively identical but brute-ly numerically distinct $\mathrm{C}$ instance, which bundles exactly two tropes: (I) the unit negative charge trope that at the actual world belongs to the electron in the relevant location, and (2) the Eiffel Tower's wrought iron trope. Call a material object whose only two tropes are (a) the wrought iron trope of the Eiffel Tower and (b) a unit negative charge trope at some non-zero distance from the Eiffel Tower, an iron-tron. The actual world contains many electrons but no iron-trons, while $w$ contains many iron-trons but no electrons. Yet the two worlds are, ex hypothesi, exactly the same in their spatiotemporal distributions of qualitative properties (setting the sortal concepts electron and iron-tron aside), including in their (qualitative) distribution of $\mathrm{C}$ instances. But this is unacceptable. If one's answer to the many-over-one requires worlds qualitatively exactly like ours to lack electrons, it is mistaken. 
To be sure, even if the 'something about' each $\mathrm{C}$ instance is a unique qualitative feature, there is much in common between the actual world and some nearby iron-tron world. However, in the qualitative case there are qualitative differences that offer the proponent of relata-specific bundle theory an explanation of why the two worlds have different objects. Relata-specific bundle theory is hardly alone in invoking some sui generis qualitative features precisely for explanatory purposes. Perhaps it is surprising that the reason electrons do not exist in some world $w^{*}$, even though it contains exactly the actual world's spatiotemporal distribution of unit negative charge and other familiar properties, is that $w^{*}$ is missing some of the actual world's distinctively metaphysical and sui generis qualitative $\mathrm{C}$ instances. But I submit that it is far more surprising to be told that $w$ from the preceding paragraph lacks electrons as a matter of brute fact.

So concludes the argument that the best version of relata-specific bundle theory requires the unique features of $\mathrm{C}$ instances invoked as the fundamental explanantia of bundling to be intrinsic, categorical, and qualitative. In short, these features cannot do the explanatory work assigned to them unless they are intrinsic and categorical, and they cannot do it well unless they are qualitative. Ultimately, then, a C instance's qualitative nature cannot just be the determinable nature of being a compresence instance. It must be a qualitatively unique determinate of that determinable. Thus the relata-specific bundle theory ontology is in a certain way highly liberal, since for each case of bundling (at least at the fundamental level), it requires a qualitatively unique $\mathrm{C}$ instance. Consequently, it requires a great multitude of qualitatively unique, fundamental bundling instances: compresence instances in spacetime that are each intrinsically qualitatively distinct from every other. As an anonymous referee notes, this multitude marks a departure from traditional Russellian monism, according to which fundamental property instances fall under a relatively small number of types that function as the building blocks of consciousness and physics. The departure is anodyne, however, since it is not crucial to panprotopsychist Russellian monism to hold that fundamental property instances align into repeatable types. Moreover, the departure is modest, since the universal uniqueness claim is compatible with groupings into types whose members co-resemble well enough to fit the building block story, even though they do not co-resemble exactly. After all, qualitative distinctness across determinates within a determinable may be quite subtle, as with distinct mass quantities that vary only infinitesimally. Relata-specific bundle theory requires no more qualitative variety across $\mathrm{C}$ instances than that.

Although neither Maurin nor Wieland and Betti focus on the issue, the relationship between a $\mathrm{C}$ instance and its bundle-ees on the version of relata-specific bundle theory that I have articulated matches the currently working notion of ground, whereby something's spatiotemporal configuration and qualitative nature necessitates-in virtue of that nature-something else's existence or nature. For a given C instance's unique intrinsic, categorical, qualitative nature is precisely what necessitates the bundling, and thus the instantiation, of its bundle-ees. And, while those bundle-ees might be capable of independent existence (more on this shortly), the best metaphysical explanation for their being as they are right nownamely, co-bundled where they are co-bundled-is that the $\mathrm{C}$ instance exists as it 
does right now. Why is my particular car green? That is, why does that trope/ universal bundle contain that greenness constituent, in the sense of 'why' relevant to fundamental metaphysics? Relata-specific bundle theory answers: Because a certain $C$ instance exists with the unique qualitative nature that it has. Since there is nothing special here about my car or greenness, the case generalizes: all property instantiations obtain because of some or other $\mathrm{C}$ instances having the unique qualitative natures that they primitively and respectively have. Thus the best version of relata-specific bundle theory entails that the world's collection of $\mathrm{C}$ instances makes up the fundamental explanatory metaphysical level, insofar as it explains why everything is qualitatively distributed as it is.

One might object that since a given $\mathrm{C}$ instance cannot exist without its bundle-ees existing, and yet they can exist without it, the bundle-ees are no less fundamental than the $\mathrm{C}$ instance, which dampens the claim that $\mathrm{C}$ instances ground their bundle-ees. But this is a confusion: $x$ can ground $y$ even if $y$ could exist in the absence of $x$, so long as in the latter case some $z$ of the same relevant kind as $x$ is around to ground $y$. Compare the perdurantist claim that a certain temporal part $x$ of persisting object $y$ grounds the fact that $y$ once had property $\mathrm{F}$. The truth of that claim does not rule out the possibility that $y$ be $\mathrm{F}$ at some past time even in worlds where $x$ never exists. Such worlds simply require some other past temporal part of $y$ to be F. Still, according to perdurantism, $x$ grounds and explains $y$ 's past F status.

Perhaps the real worry behind this objection is that some actual bundle-ees might have existed without being bundled at all, and thus might have existed in the absence of any $\mathrm{C}$ instance. For example, many trope theorists accept so-called 'free floating' tropes, which exist unbundled with other tropes (Campbell I990: 59; Ehring 20I I: 77; see also Giberman 20I4 on individual tropes as trivial bundles). This would undercut the above analogy with perdurantism, which rejects the possibility of persisting objects sans proper temporal parts. Fortunately, however, there is good reason to expect the best version of relata-specific bundle theory to require that even free-floating property instances obtain only because of some $\mathrm{C}$ instances. I mentioned the key reason why in another context above: bundle theorists do well to avoid commitment to pairs of worlds with exactly alike distributions of qualitative property instances but different inventories of electrons. Yet if the proponent of relata-specific bundle theory accepts property instances that float free not just of other typical property instances, but also of all $\mathrm{C}$ instances, then she is left with no way to avoid commitment to such problematic pairs of worlds. By contrast, if she holds that even free-floating property instances ever obtain only because of the existence of some specifically natured $\mathrm{C}$ instances, then she has a direct explanation of why otherwise qualitatively indiscernible pairs of worlds may differ as to the presence of electrons, namely, that they differ in $\mathrm{C}$ distribution.

One might worry next that relata-specific bundle theory's modal claims are insufficiently explanatory, since necessitation is insufficient for explanation. In response, I reemphasize that according to relata-specific bundle theory, C instances ground instantiation. They do not merely necessitate it as, say, my summering in Maine necessitates the number I7's being odd, or Socrates's 
singleton necessitates his being a member of it if he exists (Fine I994). To see this, consider the following six features of $\mathrm{C}$ instances:

I. Soundness: all C instances necessitate some property instantiations.

2. Completeness: all property instantiations are necessitated by some $\mathrm{C}$ instance or other.

3. Sensitivity: altering a $\mathrm{C}$ instance would correspondingly alter which properties are instantiated (at least usually and perhaps alwaysrecall that extant relata-specific bundle theorists are not clear about this).

4. Locality: specific, particular $\mathrm{C}$ instances are alone sufficient, at every world at which they exist, for specific, particular property instantiations.

5. Character: each $\mathrm{C}$ instance necessitates the property instantiations it does because of its intrinsic qualitative character.

6. Uniqueness: no property other than $\mathrm{C}$ is sufficient for all property instantiations.

By contrast, my summering in Maine's necessitating I7's oddness is not complete, sensitive, local, character-based, or unique. Socrates's singleton's necessitating his membership enjoys more of these features, but still not all of them. For example, it is not plausibly character-based, since it is unclear whether sets even have intrinsic qualitative character. I conclude that $\mathrm{C}$ is no mere necessitator of instantiation. It explains it.

Before proceeding to the main argument in the next section, it bears noting that although relata-specific bundle theory has been developed within the framework of bundle theory, its main idea is exportable. For example, a substance-attribute ontology may be fitted with a conception of instantiation qualitatively rich enough to explain why substances instantiate exactly the attributes that they do. On this suggestion, instantiation itself is so qualitatively complicated and powerful that it intrinsically has something to say about all property exemplifications, much like a noncausal 'God property'. Granted, the foregoing is a deviant and theoretically expensive version of substance-attribute theory, but its price is worth considering if no satisfactory alternative treatment of Bradley's regress or the many-over-one is forthcoming. Having acknowledged this option, I continue to focus on bundle theoretic relata-specific bundle theory. The present point is that philosophers interested in the metaphysics of consciousness need not be antecedently committed bundle theorists in order to take relata-specific bundle theory seriously.

Indeed, since a given philosopher of mind can dismiss the potential independent philosophical value of relata-specific bundle theory only if she is happy to commit to a metaphysics of properties that independently addresses or sidesteps the many-over-one and Bradleyan concerns-such as various forms of property nominalism or (perhaps) states of affairs ontologies-and since these views are all independently highly controversial (even if defensible), many philosophers of mind are such that their prudent caution toward the metaphysics of properties leaves no reason to dismiss the philosophical promise of relata-specific bundle theory. 


\section{Relata-Specific Panprotopsychism}

The argument that the best version of relata-specific bundle theory is a species of constitutive Russellian panprotopsychism is an instance of modus ponens with the following premises:

Premise I: According to the best version of relata-specific bundle theory, some C instances are at once (a) constitutive of fundamental physical dispositional structure, (b) constitutive of macroconsciousness, and (c) protophenomenal.

Premise 2: If some of a theory's proposed property instances satisfy (a)-(c) then the theory is a species of constitutive Russellian panprotopsychism.

Premise 2 follows from Chalmers's characterization of constitutive Russellian panprotopsychism. Below I defend premise I by arguing for its conjuncts.

\section{Argument for (ra)}

According to the best version of relata-specific bundle theory, every fundamental-physical-disposition-realizing quiddity $\mathrm{F}$ is such that some or other $\mathrm{C}$ instances are required, and certain $\mathrm{C}$ instances are individually sufficient, for the instantiation of $\mathrm{F}$. To see this, notice that $\mathrm{C}$ instances are required for bundling and that fundamental physical dispositions are realized only if some tropes (or universals) are bundled. Just as importantly, $\mathrm{C}$ instances are generally required and respectively individually sufficient for the dispositions themselves, independently of any (other) quiddities. For, again, the dispositions are ever present only in bundles (since bundles are required for any case of instantiation), and $\mathrm{C}$ instances are required for bundling. Thus, according to the best version of relata-specific bundle theory, $\mathrm{C}$ instances have what is important about constituting fundamental physical structure, namely, their special qualitative nature and spatiotemporal configuration jointly ground it. (Recall from section 2 that $\mathrm{C}$ instances have spatiotemporal locations, as required by bundle theory's need to keep its posits in spacetime.)

To sum up: $\mathrm{C}$ instances ground fundamental physical structure because (I) fundamental physical structure is grounded by the instantiation of the relevant physical properties, (2) the instantiation of those properties is in turn grounded by the presence and intrinsic nature of the relevant $\mathrm{C}$ instances, and (3) grounding is transitive. (For a reminder of why (2) is true, see above in section 2 the discussion of how C instances' necessitation of property exemplification is sound, complete, sensitive, local, character-based, and unique.)

To reiterate: $\mathrm{C}$ instances genuinely ground fundamental physical structure; it is not the case that the $\mathrm{C}$ instances account for bundling the relevant properties only in the superficial sense that a rope bundles some sticks. ${ }^{\mathrm{I}}$ Rather, the fundamental physical properties in question are ever jointly instantiated only because of the

\footnotetext{
${ }^{\mathrm{I}}$ I thank an anonymous referee for this example.
} 
relevant $C$ instances' existing and having the natures that they do, and the instantiations obtain exactly as they do as soon as the relevant $\mathrm{C}$ instances exist. No such relationships hold between any sticks and ropes.

The foregoing considerations yield the first premise of the argument for (ra):

I. According to the best version of relata-specific bundle theory, $\mathrm{C}$ instances, due to their qualitative nature and spatiotemporal configuration, ground the instantiation of fundamental physical dispositional structure by grounding the bundling of (and corresponding instantiations of) the properties relevant to that structure.

The second premise follows from the working notion of 'constitutive':

2. If some qualitative property instances, $\Phi_{\mathrm{x}}, \Psi_{\mathrm{y}}, \ldots$, due to their qualitative nature and spatiotemporal configuration, ground the instantiation of another property (or ground the instantiation of a structure by grounding the instantiation of the properties relevant to it), then $\Phi_{\mathrm{x}}, \Psi_{\mathrm{y}}, \ldots$. are constitutive of that property (or structure).

It follows by modus ponens that:

Ia: According to the best version of relata-specific bundle theory, some $\mathrm{C}$ instances are constitutive of fundamental physical dispositional structure.

There is an important consequence of ( $\mathrm{ra}$ ) that bears emphasis at this point: if the best version of relata-specific bundle theory is true, then physics cannot be narrow. For on the narrow conception, dispositional structure does not require any categorical qualitative ground. However, if the best version of relata-specific bundle theory is true, then there must be 'quiddities' of a certain kind in order for there to be any dispositional structure, since $\mathrm{C}$ instances' primitive categorical qualitative natures are precisely what the best version of relata-specific bundle theory deploys to explain how the dispositional features of the dispositional structure become co-instantiated.

\section{Argument for $(\mathrm{I} b)$}

Following orthodoxy, let us assume that macrophysical properties like an elephant's color and texture are grounded by microphysical properties. According to relata-specific bundle theory, the microphysical properties are grounded by $\mathrm{C}$ instances. Given the going connection between grounding and constituting, and given the transitivity of grounding, it follows that, according to relata-specific bundle theory, $\mathrm{C}$ instances that ground microphysical structure also ground and constitute macrophysical properties like color and texture. This leads to the first premise of the argument for $(\mathrm{I} b)$ :

Premise I. According to relata-specific bundle theory, the $\mathrm{C}$ instances that bundle the properties of microphysical entities are (when appropriately 
grouped and configured) constitutive of macrophysical properties like color and texture.

Of course, to say that some properties are constitutive of others does not entail that the first are responsible for the bundling of the second. But in the case of $\mathrm{C}$ instances, this is a natural connection to draw. Suppose some micro entities $x_{\mathrm{I}}, x_{2}, \ldots x_{\mathrm{n}}$ compose a macro entity $y$. Suppose further that the properties of $x_{1}, x_{2}, \ldots x_{\mathrm{n}}$ collectively are constitutive of the macro properties of $y$, and that, for each $x_{i}$, there is a $\mathrm{C}$ instance that bundles its properties. Question: What bundles the macro properties of $y$ ? Is the relata-specific bundle theorist to posit an additional 'macro' $\mathrm{C}$ instance, entirely disjoint from all $\mathrm{C}$ instances that bundle any of $x_{\mathrm{I}}$, $x_{2}, \ldots x_{\mathrm{n}}$, which is alone responsible for the bundling of $y$ 's macro properties? Although the issue has not-to my knowledge-been discussed in the young literature on relata-specific bundle theory, I submit that the best version of relata-specific bundle theory answers this question negatively. That is, the best version will hold that the $\mathrm{C}$ instances that bundle the properties of $x_{\mathrm{I}}, x_{2}, \ldots x_{\mathrm{n}}$ are collectively responsible for the bundling of $y$ 's macro properties. Thus there will be some macro properties such that they are not bundled by a single $\mathrm{C}$ instance, but rather by a plurality of $\mathrm{C}$ instances.

The second premise in the argument for ( $\mathrm{Ib}$ ) utilizes this observation about collective $\mathrm{C}$ instance bundling. The premise follows from the conjunction of two claims. The first is that both macrophysical and macrophenomenal properties are instantiated by macro entities like humans and elephants. The second is relata-specific bundle theory's central claim (outfitted with the allowance of collective bundling), namely, that relata-specific $\mathrm{C}$ instances are required to solve the many-over-one:

Premise 2. According to relata-specific bundle theory, some configuration of C instances is required to explain the co-instantiation of macrophysical properties and macrophenomenal properties in conscious macro entities.

The third premise builds upon the case for collective bundling made above, offering a more specific diagnosis of why relata-specific bundle theory should not allow separate macro-bundling $\mathrm{C}$ instances:

Premise 3. According to relata-specific bundle theory, if the $\mathrm{C}$ instances described in premise (2) were not numerically identical with the $\mathrm{C}$ instances responsible for fundamental microphysical property instantiation then relata-specific bundle theory would lead to overdetermination, interactionism, or epiphenomenalism in accounting for facts about macro properties.

If the identification does not hold, then the $\mathrm{C}$ instances grounding the microphysical properties relevant to a given elephant's physical status would-by premise (I) determine the macrophysical properties of the elephant, and yet those 
macrophysical properties would also (separately) be determined by some numerically distinct $\mathrm{C}$ instance that determines the co-exemplification of macroconsciousness and macrophysical properties in the elephant. Thus the elephant's color, for example, would be explained by two different sets of broadly physical property instances, namely, the $\mathrm{C}$ instances of the micro and the proposed $\mathrm{C}$ instance of the macro. It follows that the relata-specific bundle theorist would either have to accept causal or explanatory overdetermination of the macrophysical properties of the elephant, or else treat the $\mathrm{C}$ instance grounding the elephant's color as not even broadly physical. But this last move leads either to a sort of interactionism, according to which the macro-grounding $\mathrm{C}$ instance is not physical but grounds physically causally efficacious entities, or else to a radical macro epiphenomenalism, according to which the macro properties of macro entities, whether physical or phenomenal, are causally inert.

To accept any of the consequences listed in premise (3) would be costly for relata-specific bundle theorists. Fortunately, doing so is unnecessary since the option to identify the $\mathrm{C}$ instances that ground microphysics with the $\mathrm{C}$ instance(s) that ground macroconsciousness is open to the relata-specific bundle theorist, in the form of collective bundling. After all, as premise (ii) states, the relata-specific bundle theorist must invoke some $\mathrm{C}$ instance(s) to ground the co-instantiation of the physical and phenomenal anyway. She might as well do so in a way that is both ontologically economical and devoid of serious theoretical costs like overdetermination, interactionism, and epiphenomenalism. I thus arrive at the fourth premise:

Premise 4: The best version of relata-specific bundle theory does not require overdetermination, interactionism, or epiphenomenalism in order to account for the $\mathrm{C}$ instances described in premise (2), and thus to account for facts about macro property instantiation.

By modus tollens on premises (3) and (4), I arrive at ( $\mathrm{Ib}$ ):

(Ib): According to the best version of relata-specific bundle theory, the $\mathrm{C}$ instances constitutive of microphysics are also constitutive of macroconsciousness.

\section{Argument for (IC)}

I assume that the relata-specific bundle theorist takes $\mathrm{C}$ instances to be nonconscious. This is not required by relata-specific bundle theory, however, and some relataspecific bundle theorists might prefer panpsychism to panprotopsychism (more on this below). Nonetheless, the assumption seems advisable. Thus, by assumption:

I. According to relata-specific bundle theory, $\mathrm{C}$ instances are not conscious.

I showed above in section 2 that the best version of relata-specific bundle theory treats $\mathrm{C}$ instances as nonstructural. Thus,

2. According to relata-specific bundle theory, $\mathrm{C}$ instances are nonstructural. 
On the best version of relata-specific bundle theory, $\mathrm{C}$ instances are schematically described to embody exactly the qualitative natures that a priori entail property bundling and the associated property distributions. Thus,

3. According to relata-specific bundle theory, truths about $\mathrm{C}$ instances a priori entail truths about the properties that they constitute, including macrophenomenal properties, for the relevant $\mathrm{C}$ instances are stipulated to be of just the qualitative sort that necessitate the relevant property instantiations.

Given the definition of 'protophenomenal', it follows from (I)-(3) and (Ib) that

Ic: According to the best version of relata-specific bundle theory, the $\mathrm{C}$ instances that constitute microphysics and macroconsciousness are protophenomenal.

This concludes the argument for premise I of the original modus ponens.

\section{Objections and Replies}

I anticipate four objections. First, relata-specific bundle theory is unremarkable since any attempted solution to the many-over-one is explanatorily pertinent to the distribution of both physical and phenomenal properties, including their co-instantiation. Yet surely orthodox instantiation theories are not versions of Russellian monism, so relata-specific bundle theory must not be either.

This objection jumps erroneously from the observation that orthodox approaches to the many-over-one serve as 'explanatorily pertinent' to the conclusion that relata-specific bundle theory is unremarkable. What is special about relata-specific bundle theory is that it bases its explanatory power explicitly on the primitive, unique, categorical qualitative natures of all the particular and varied $\mathrm{C}$ instances, and their modal connection to property instantiation. Orthodox instantiation or compresence theories do nothing of the sort. Yet this difference is precisely what makes relata-specific bundle theory a version of Russellian monism. If $\mathrm{C}$ instances were not categorically qualitatively special and correspondingly responsible for securing property instantiations 'as soon as' they exist, then they would not count as (fully) grounding physics or consciousness, nor would they solve Bradley's regress.

According to the second objection, relata-specific bundle theory fails to meet a necessary condition for being a version of Russellian monism, namely, it fails to distance itself from narrow physicalism/functionalism. Sure, relata-specific bundle theory, like Russellian monism, provides a certain kind of sufficiency base for everything, including consciousness. But it does so only by relying on the relationship between narrow physical structure and macro consciousness. Thus any narrow physicalist or functionalist could accept relata-specific bundle theory Russellian monism, which shows that it is not a legitimate version of Russellian monism. ${ }^{2}$

\footnotetext{
${ }^{2}$ I thank an anonymous referee for this objection.
} 
This objector is confused about relata-specific bundle theory. Relata-specific bundle theory explicitly posits sui generis spatiotemporally located property instances that are intrinsic, qualitative, and categorical. It thus is straightforwardly incompatible with narrow physicalism and any associated functionalisms, as explained in the remarks following the argument for (ra) above. Moreover, relata-specific bundle theory is predicated on the claim that these sui generis property instances (the $\mathrm{C}$ instances) are metaphysically explanatory of all other property instances. Consequently, relata-specific bundle theory does not lean on the relationship between microphysics and the macro world in order to explain consciousness fundamentally. What fundamentally explains all property instantiations, on relata-specific bundle theory, are $\mathrm{C}$ instances. This is a far cry from narrow physicalism.

The third objection maintains that since Chalmers states that we know nothing about protophenomenal properties, and yet we know that $\mathrm{C}$ instances are bundling instances, $\mathrm{C}$ is unduly different from the sort of 'quiddities' envisioned by Russell or Chalmers.

This objection is mistaken. Chalmers (2015) allows that we can describe protophenomenal properties schematically, and that is all the relata-specific bundle theorist does with respect to $\mathrm{C}$ instances. It is not as though relata-specific bundle theory tells us anything specific about the $\mathrm{C}$ instances' intrinsic natures or how precisely they work to explain instantiation-they are not red or velvety or bitter. We just know them schematically as special categorical properties capable of grounding both microphysics and macroconsciousness precisely because of their qualitative natures.

The fourth objection, like the second, says that there is an important feature of Russellian monism that relata-specific bundle theory Russellian monism lacks, namely, a connection to phenomenal consciousness sufficient to close, or at least lessen, the epistemic/explanatory gap between the physical and the phenomenal. It is clear that panpsychist Russellian monism has this sort of connection, since it attributes phenomenal consciousness to the fundamental physical entities. But the panprotopsychist version of Russellian monism, the objection goes, is supposed to have this sort of connection as well. For example, so-called panqualityism (Feigl I970; Coleman 2012), according to which fundamental physical entities instantiate special experience-able properties ('qualities') that jointly configure to yield macro-phenomenal experiences, is thought to help bridge the gap. The bridge forms because, while qualities of fundamental particles are not themselves experienced, they are of the same basic type as the experienced macro-qualities that they ground. By contrast, the objection continues, $\mathrm{C}$ instances are completely different from phenomenal experiences, leaving the epistemic/explanatory gap open. ${ }^{3}$

I have one direct response and two indirect responses to this fourth objection, which jointly shed light on the dialectical importance of relata-specific bundle theory Russellian monism.

${ }^{3}$ I thank David Chalmers for this objection. 
The direct response is that the objection sells relata-specific bundle theory Russellian monism short. While it is true that $\mathrm{C}$ instances are not the panqualityist's qualities, they are objectively qualitative. Thus they (theoretically) are capable of being perceptually experienced. It conceptually accords with relata-specific bundle theory that we could see, hear, and touch $\mathrm{C}$ instances. Yet the $\mathrm{C}$ instances also are highly specialized, highly varied, and presumably unlike anything we have experienced. If we did perceptually experience the whole array of them needed to ground, say, a particular brain state, there is no saying what that complex experience would be like. Unlike a mere configuration of standard physical properties, it might well inform us about the associated phenomenal state in a way that lessened the epistemic/explanatory gap. Obviously, this direct response to the fourth objection is highly speculative-but not inappropriately so. For example, it is no more speculative than parallel defenses of panpsychism or panqualityism. There is at present little more than speculation supporting the suggestion that fundamental physical entities have consciousness or panqualityist qualities, or that such qualities would close the epistemic/explanatory gap.

The first indirect response to the fourth objection is that there is room in tenable conceptual space for panpsychist or panqualityist versions of relata-specific bundle theory Russellian monism (recall that treating $\mathrm{C}$ instances as nonconscious was an assumption). Granted, this would saddle relata-specific bundle theory with commitments that its actual proponents do not endorse. But that is beside the point. These species of relata-specific bundle theory Russellian monism have all the relevant features of the species discussed up to this point. The difference is simply that either phenomenality is added to instances of $\mathrm{C}$ (panpsychist version) or status as 'qualities' of the relevant kind is added to instances of C (panqualityist version). This response is indirect because it leaves unaddressed the objector's claim that $\mathrm{C}$ instances as they have been discussed prior to the objection do not lessen the epistemic or explanatory gap. Still, it yields a species of relata-specific bundle theory Russellian monism that lessens those gaps exactly as much as do other panpsychist or panqualityist versions of Russellian monism.

Like the first indirect response, the second makes no attempt to show that $\mathrm{C}$ as previously discussed lessens the epistemic/explanatory gap. However, it does not invoke panpsychism or panqualityism, either. It simply emphasizes that relataspecific bundle theory Russellian monism has many important features from the perspective of the philosophy of mind. It rules out zombies, Mary, and orthodox physicalism without violating causal closure or denying causal efficacy to the mental. Moreover, it does all this without facing the sort of conceivability argument that Chalmers (2015) poses to panqualityism - the chief example of a panprotopsychist Russellian monism that putatively lessens the epistemic/explanatory gap. For, while Chalmers may be correct that it is conceivable to have the configured qualities described by panqualityism and yet no phenomenality, it is inconceivable to have the configured $\mathrm{C}$ instances described by relata-specific bundle theory without the associated phenomenality. To hold otherwise is a conceptual confusion, analogous to holding that it is conceivable to travel through spacetime from one Lewisian world to another, or to separate an extended simple object into proper parts. If the putative inability to lessen the epistemic/explanatory gap keeps relata-specific bundle 
theory from having the status of 'panprotopsychism', this second indirect response goes, then so be it. Simply drop the claim that the best version of relata-specific bundle theory is panprotopsychist and use the neologism paninstantiationism instead. What is important is that paninstantiationism has the above-mentioned dialectical features of Russellian monism plus immunity to conceivability arguments. Whatever the value of lessening the explanatory or epistemic gap may be, it is not obviously greater than the value of immunity to conceivability arguments.

\section{Conclusion}

One interesting upshot of the present discussion is that even those who deny that physics involves the quiddities envisioned by Russell must face a version of Russellian monism with the dialectical features that Chalmers highlights. For, as emphasized in the argument for (ra) above, relata-specific bundle theory entails that quiddity distribution is required for property instantiation in general, even if none of Russell's suggested quiddities are needed to realize physical structure. To see this, notice that even on the narrow conception of the physical, the dispositional roles distinctive of mass, charge and the like are bundled in the sense that they are instantiated together in a certain spatiotemporal configuration. Yet mass values, charge values, and spatiotemporal relational structure all could have existed without being co-configured as they are. Thus relata-specific bundle theory requires categorical $\mathrm{C}$ instances to explain narrowly construed physics itself, even on the assumption that none of Russell's quiddities are needed.

To see better that $\mathrm{C}$ instances are not just versions of Russell's quiddities (despite being quiddities enough for Russellian monism), notice that relata-specific bundle theory Russellian monism, while ruling out narrow physics, allows for the conceivability and possibility of what we might call 'narrow-ish' physics. That is, relata-specific bundle theory allows for physics to be devoid of quiddities instantiated by any material objects, spacetime points, fields, or other plausible substantial particulars relevant to the role-playing of physical dispositional roles. Such physics is to that extent in line with the narrow conception. However, what physics cannot lack, according to relata-specific bundle theory (and in violation of the narrow conception), are $\mathrm{C}$ instances, which primitively instantiate their own quiddities at locations-quiddities not instantiated by material objects, points, or fields.

At the risk of some hyperbole, one might say that a corresponding lesson of the present discussion is that the metaphysics of properties is, in a certain sense, deeper than the mind-body problem. For the former contains a well-motivated theory that closes an otherwise open and extensive dialectical space into which the latter regularly travels. If the best version of relata-specific bundle theory is true, then zombies and Jackson's Mary are inconceivable and orthodox physicalism is false, quite independently of whether physics includes the putative role-players of dispositional structure that Russell, Chalmers, and other theorists have considered antecedently. 


\section{References}

Armstrong, David Malet. (1978) Realism and Nominalism. Cambridge: Cambridge University Press. Armstrong, David Malet. (1989) Universals: An Opinionated Introduction. Boulder: Westview.

Bealer, George. (I993) 'Universals'. Journal of Philosophy, 90, 5-32.

Bohn, Einar Duenger. (2009) 'Must There Be a Top Level?'. Philosophical Quarterly, 59, I93-20I.

Bradley, F. H. (1893) Appearance and Reality. London: Swan Sonnenschein. https://openlibrary.org/ books/OLI9108202M/Appearance_and_reality.

Campbell, Keith. (I990) Abstract Particulars. Oxford: Basil Blackwell.

Carmichael, Chad. (2010) 'Universals'. Philosophical Studies, I 50, 373-89.

Chalmers, David J. (1996) The Conscious Mind: In Search of Fundamental Theory. Oxford: Oxford University Press.

Chalmers, David J. (2003) 'Consciousness and Its Place in Nature'. In Stephen P. Stich and Ted A. Warfield (eds.), Blackwell Guide to the Philosophy of Mind (Oxford: Blackwell), IO2-42.

Chalmers, David J. (2015) 'Panpsychism and Panprotopsychism'. In Torin Alter and Yujin Nagasawa (eds.), Consciousness in the Physical World: Perspectives on Russellian Monism (Oxford: Oxford University Press), 246-76.

Coleman, Sam. (2012) 'Mental Chemistry: Combination for Panpsychists'. Dialectica, 66, I37-66.

Effingham, Nikk. (2020) 'Mereological Nominalism'. Philosophy and Phenomenological Research, IOO, I60-85.

Ehring, Douglas. (20II) Tropes: Properties, Objects, and Mental Causation. Oxford: Oxford University Press.

Feigl, Herbert. (1970) 'Mind-Body, not a Pseudo-Problem'. In C. V. Borst (ed.), The Mind-Brain Identity Theory: A Collection of Papers (London: MacMillan), 33-4I.

Fine, Kit. (1994) 'Essence and Modality: The Second Philosophical Perspectives Lecture'. Philosophical Perspectives, 8, I-I6.

Fuhrmann, André. (I99I) 'Tropes and Laws'. Philosophical Studies, 63, 57-82.

Giberman, Daniel. (2014) 'Tropes in Space'. Philosophical Studies, I67, I 53-72.

Goff, Philip. (2017) Consciousness and Fundamentality. Oxford: Oxford University Press.

Jackson, Frank. (1982) 'Epiphenomenal Qualia'. Philosophical Quarterly, 32, I27-36.

Kim, Jaegwon. (I987) “"Strong" and "Global" Supervenience Revisited'. Philosophy and Phenomenological Research, 48, 3 I 5-26.

MacBride, Fraser. (20 I I) 'Relations and Truthmaking'. Proceedings of the Aristotelian Society, I I I, I6I-79.

Maurin, Anna-Sofia. (2002) If Tropes. Dordrecht: Kluwer.

Maurin, Anna-Sofia. (2015) 'States of Affairs and the Relation Regress'. In Gabriele Galluzzo and Michael J. Loux (eds.), The Problem of Universals in Contemporary Philosophy (Cambridge: Cambridge University Press) I95-2I 4.

Maurin, Anna-Sofia. (20I6) 'Tropes: For and Against'. In Francesco F. Calemi (ed.), Metaphysics and Scientific Realism: Essays in Honour of David Malet Armstrong (Boston: De Gruyter) 85-IO4.

O'Leary-Hawthorne, John, and Cover, J. A. (I998) 'A World of Universals'. Philosophical Studies, 9I, 205-I9.

Rodriguez-Pereyra, Gonzalo. (2002) Resemblance Nominalism: A Solution to the Problem of Universals. Oxford: Oxford University Press.

Russell, Bertrand. [1927] (1992) The Analysis of Matter. London: Routledge.

Schiffer, Stephen. (1987) Remnants of Meaning. Cambridge, MA: MIT Press.

Stoljar, Daniel. (200I) 'Two Conceptions of the Physical'. Philosophy and Phenomenological Research, 62, 253-8I.

Wieland, Jan Willem, and Arianna Betti. (2008) 'Relata-Specific Relations: A Response to Vallicella'. Dialectica, 62, 509-24.

Williams, Donald Cary. (1953) 'On the Elements of Being I'. Review of Metaphysics, 7, 3-I8. 